\title{
Cuidado e Empoderamento: a construção do sujeito responsável por sua saúde na experiência do diabetes'
}

\section{Care and Empowerment: the construction of the subject responsible for his own health in the experience of diabetes}

\author{
Andréia Aparecida Ferreira Lopes \\ Universidade Estadual de Campinas. Faculdade de Ciências Médi- \\ cas. Departamento de Saúde Coletiva. Programa de Pós-Graduação \\ em Saúde Coletiva. Campinas, SP, Brasil. \\ E-mail: andreia-fœuol.com.br
}

\section{Correspondência}

Rua Tessália Vieira de Camargo, 126.

Campinas, SP, Brasil. CEP 13083-887.

10 texto foi elaborado com base nos dados da pesquisa de pós-doutorado "Cuidado de si e empoderamento: os cuidados do diabetes a partir da experiência associativa”, financiada pela Fundação de Amparo à Pesquisa do Estado de São Paulo (FAPESP) (processo n 2011/227512), desenvolvida no Departamento de Saúde Coletiva da Faculdade de Ciências Médicas da Unicamp, sob supervisão da Profa. Dra. Ana Maria Canesqui. 


\section{Abstract}

Based on an analysis of the literature on patient empowerment in the field of diabetology, I discuss the impact of this perspective on the meanings of changes in the relations of care, and explore implications to the position occupied by health professionals and patients. The analysis considers the difficulties and embarrassments mentioned by health professionals regarding the changes that are required by patient empowerment. Through an anthropological approach, the analysis is supported by theoretical conceptions about the contrast between the logic of choice and the logic of care, and problematizes the difference among the representations of biomedicine agents and patients, based on the opposition between the individual/person models. The analytical course allows to conclude that it is necessary to relativize the idea that patient empowerment represents an increase in individualism in health care relationships. This contributes to include other nuances in the social scientists' reflections on the current tendency of attributing to individuals the responsibility for their own health.

Keywords: Empowerment; Delivery of Health Care; Diabetes Mellitus; Person; Anthropology of Health.

\section{Introdução}

Nas análises socioantropológicas acerca do impacto dos saberes e práticas da biomedicina sobre as formas de cuidado com a saúde, e sobre os estilos de vida atuais, muito se discute a respeito da tendência de responsabilização dos indivíduos por sua própria saúde (Rose, 2001, 2007; Rabinow, 2002; Featherstone, 1991).

Para Rose (2007) a biopolítica² contemporânea se caracteriza pelo surgimento de novas racionalidades e tecnologias de governo do "liberalismo avançado", o que produz a reorganização dos poderes do Estado. Uma característica desse quadro é a "devolução" aos indivíduos de muitas de suas responsabilidades sobre a gestão da saúde, as quais, durante o século $\mathrm{XX}$, haviam se tornado responsabilidade do aparato formal de governo. O aumento das obrigações de indivíduos, famílias e certas comunidades em gerenciar sua própria saúde responderia ao processo de intensificação e generalização das estratégias de promoção da saúde desenvolvidas a partir da segunda metade do século XX, responsável pelo aparecimento da indústria privada de seguro à saúde e pelo surgimento de uma nova "vontade de saúde", crescentemente capitalizada por um leque de empresas que vão desde companhias farmacêuticas até o comércio de alimentos (Rose, 2001).

A presente análise pretende contribuir para esse debate ao explorar os significados das transformações nas relações de cuidado ${ }^{3}$ prefiguradas pela abordagem do empoderamento desenvolvida no contexto da assistência à saúde dos diabéticos. 0 interesse por essa abordagem se deve à forma específica como ela propõe a transformação do estatuto do paciente na relação com os provedores de cuidado. Como apontam Funnell e Anderson (2003a),

2 O conceito de biopolítica tem origem na obra de Michel Foucault, cuja tese é a de que nas sociedades ocidentais, a partir do século XVIII, as autoridades políticas em aliança com muitas outras se orientaram no sentido de assumir a função de gerir a vida. Como coloca Foucault (1988, p. 131), centrando-se "no corpo transpassado pela mecânica do ser vivo e como suporte dos processos biológicos: a proliferação, os nascimentos e a mortalidade, o nível de saúde, a duração da vida, a longevidade, com todas as condições que podem fazê-los variar; tais processos são assumidos mediante toda uma série de intervenções e controles reguladores: uma biopolítica da população".

3 Como aponta $\mathrm{Mol}(2008$, p. 1), nas discussões em torno de cuidado com a saúde, geralmente care e cure são consideradas noções diferentes. Care refere-se a atividades como lavar, alimentar, fazer curativo, enfim, aquilo que torna a vida diária tolerável. Cure remete à ideia da possibilidade de cura (healing) e se aplicaria às intervenções no curso de uma doença. Adoto aqui a mesma disposição dessa autora ao não distinguir esses dois processos. Além do fato de que muitas vezes os tipos de atividade se sobrepõem, atualmente muitas doenças têm um caráter crônico e seu tratamento não leva à cura, mas procura tornar a vida mais tolerável. Ou seja, seu tratamento é uma forma de cuidado. Assim, neste artigo, o termo cuidado caracteriza as práticas e relações estabelecidas com o tratamento do diabetes envolvendo o próprio paciente e os vários agentes do sistema de assistência à saúde. 
o paradigma do empoderamento recebe influências de, e mantém conexões teóricas com, um leque mais amplo de abordagens que atualmente procuram superar os desafios impostos à assistência das doenças crônicas ${ }^{4}$.

A estratégia analítica utilizada aqui é a consideração da proposta de empoderamento do paciente diabético como uma expressão exemplar do quadro mais amplo de sistemas de valores relacionados à responsabilização individual pela saúde, ao mesmo tempo em que procura dar relevo às suas características específicas. $\mathrm{O}$ objetivo é problematizar as transformações que a condição de empoderamento representa para a relação entre paciente e profissionais da saúde, e para a posição de cada um dos lados nessa relação. A discussão orienta-se em testar a hipótese de que a responsabilização do indivíduo pela própria saúde representaria um incremento do individualismo sobre as relações de assistência à saúde.

Se por um lado esse caráter individualista implica o aumento dos encargos do indivíduo na gestão de sua saúde, por outro lado, os dados colhidos apontam um maior grau de complexidade nessa questão. As ideias de "autonomia do paciente na gestão de seu tratamento", e de "capacidade para fazer escolhas informadas" - que, como será visto adiante, descrevem a condição do paciente empoderado - representariam realmente o avanço do individualismo nas sociedades contemporâneas como frequentemente se interpreta o aumento da responsabilização do indivíduo pela própria saúde? As reflexões alcançadas com a presente análise mostram que essa não é uma interpretação que faz jus ao impacto que o empoderamento do paciente pode ter para as relações de assistência à saúde.

A abordagem do empoderamento do paciente diabético abrange um conjunto de medidas que discutem formas técnicas e éticas de como deve se orientar a relação entre paciente e profissionais da saúde. Essa abordagem pode ser compreendida como uma proposta para melhorar a forma de relaciona- mento entre os pacientes diabéticos e o serviço de assistência à saúde. É com essa estratégia básica que os autores da abordagem do empoderamento visam a melhoria nos resultados do tratamento da enfermidade.

Foram analisadas as publicações de um grupo relativamente pequeno de pesquisadores norte-americanos, que se destaca pela produção mais constante sobre o tema do empoderamento no campo da diabetologia. Entre esses pesquisadores destacam-se Martha Funnell e Robert Anderson, ambos vinculados à Universidade de Michigan e mantêm certa constância em publicações conjuntas ao longo de 30 anos desde a década de $1980^{5}$. Um aspecto da formação desses pesquisadores tornou-se especialmente significativo: nenhum deles é médico. Eles têm formação nas áreas de enfermagem, psicologia e sociologia, o que indica o perfil profissional daqueles que estariam mais diretamente relacionados com as práticas que envolvem orientação e acompanhamento do paciente no itinerário de tratamento das instituições de saúde.

A localização desse grupo de pesquisa resultou do levantamento de artigos sobre empowerment na revista Diabetes Care, uma publicação patrocinada pela American Diabetes Association (ADA), instituição muito influente no campo norte-americano da assistência aos diabéticos, contando com instituições universitárias, agências federais e outras organizações.

O interesse pelos autores norte-americanos se deve ao quadro mais amplo da pesquisa em andamento, que procura avaliar a influência da perspectiva do empoderamento nas práticas das associações de diabéticos da cidade de São Paulo. Conforme mostrado em pesquisa (Lopes, 2010), na coordenação de atividades locais, as associações paulistanas orientam-se pelo debate desenvolvido no cenário internacional, atribuindo destaque especial aos congressos da ADA. Existe uma estreita interlocução entre os dirigentes locais e internacionais dessas instituições, sendo que no âmbito das

\footnotetext{
4 Ao longo dos trabalhos de R. Anderson e M. Funnell reconhece-se, por exemplo, as abordagens do cuidado colaborativo (collaborative care) e da problem-directed education como semelhantes à do empoderamento (Funnell; Anderson, 2003b, p. 457). Por outro lado, assim como o caso da motivational interviewing, a estratégia de empoderamento do paciente incorporaria a abordagem do cuidado centrado no paciente (patient-centered care) (Funnell; Anderson, 2003a, p. 131).

5 Outros três autores são colaboradores das pesquisas: Russell Glasgow, Mark Peyrot e Katie Weinger.
} 
associações e dos profissionais a elas relacionados a ADA constitui-se como referência em suas diretrizes para a assistência aos diabéticos.

A partir do material inicial reunido, o levantamento de artigos dirigiu-se à produção de Robert Anderson e seus colaboradores fora da Diabetes Care, abrangendo revistas como The Diabetes Educator, Diabetes Spectrum, Patient Education and Counseling, entre outras, no período desde o início dos anos de 1980 até 2011. Foram selecionados para análise os textos que se referiam diretamente à perspectiva do empoderamento. 0 objetivo era localizar eixos de articulação no desenvolvimento dessa perspectiva ao longo das experiências de intervenção e de diálogo com os atores e outras perspectivas do campo da educação em diabetes.

Neste artigo a análise tem início com a construção de um breve quadro acerca de alguns significados relacionados ao conceito de empoderamento, procurando demarcar a especificidade da proposta desenvolvida no campo do diabetes. Desenvolve-se em seguida uma discussão sobre os dados referentes às dificuldades e aos incômodos apontados pelos profissionais da saúde ao tentarem modular suas relações com os pacientes por meio da perspectiva do empoderamento.

Por um lado, são consideradas as elaborações acerca do contraste entre a lógica da escolha e a lógica do cuidado (Mol, 2008). Com isso chama-se a atenção para o caráter moral da ação de cuidado, destacando-se algumas disposições que essa prática requer dos atores: a impossibilidade do julgamento separado da ação; a tenacidade e adaptação; o "deixar para lá". Por outro lado, os dados são confrontados com o debate da antropologia em torno da oposição dos modelos indivíduo/pessoa. Com isso, chama-se a atenção para algumas diferenças das representações entre profissionais da saúde e pacientes, considerando o modo como a condição destes últimos enquanto pessoas sob o prisma da classe de idade pode ser significativa para compreender as dificuldades nas relações de assistência. Considera-se, ainda, o significado que a condição de "paciente" tem para essa relação - que se caracteriza pela "longa duração" -, na qual o tom da "conversa" sobre os mal-estares acaba por integrar conteúdos emocionais inesperados segundo o padrão de relação tradicional.

\section{Empoderamento versus obediência e aderência}

Em sentido mais amplo, o desenvolvimento conceitual do empoderamento desde a década de 1970 tornou-o multifacetado, tendo recebido diversas influências teóricas e políticas. Esse processo inicia-se com os movimentos de autoajuda, passa pelas reflexões da psicologia comunitária nos anos 1980 e ganha novos contornos com os movimentos em torno do direito de cidadania nas diversas esferas sociais, entre elas a da saúde, a partir dos anos 1990 (Carvalho, 2004).

O conceito de empowerment é considerado um dos pilares que embasam o modelo da promoção da saúde que vem orientando as políticas de saúde em diferentes países (Carvalho; Gastaldo, 2008). Por seu lado, o conceito de promoção da saúde tem recebido diversas influências segundo os atores técnicos e sociais envolvidos em sua elaboração ao longo dos últimos 30 anos. Segundo Buss (2009), os vários sentidos envolvidos na conceituação de promoção da saúde reúnem-se em dois grandes grupos. Por um lado, a promoção da saúde consistiria "nas atividades dirigidas à transformação dos comportamentos dos indivíduos, focando nos seus estilos de vida e localizando-os no seio das famílias e, no máximo, no ambiente das 'culturas' da comunidade em que se encontram" (Buss, 2009, p. 22). Nesse sentido a estratégia educativa seria central nas atividades de promoção da saúde. Por outro lado, o sentido moderno da promoção da saúde tem um enfoque "mais amplo e abrangente, procurando identificar e enfrentar os macrodeterminantes do processo de saúde-doença e buscando transformá-los favoravelmente na direção da saúde" (Buss, 2009, p. 37). As estratégias se desenvolveriam de forma mais integrada e intersetorial, supondo a participação da população em sua formulação e implementação (p. 39). No plano individual, a ideia de empowerment introduzida na Carta de Ottawa - $1^{\text {a }}$ Conferência Internacional sobre Promoção da Saúde, realizada em 1986 - promove o redimensionamento da perspectiva da educação em saúde, de modo a orientar o processo de capacitação (aquisição de conhecimentos) e de consciência política enquanto uma das ações centrais da promoção da saúde, no sentido do 
desenvolvimento de "habilidades pessoais" (Buss, 2009, p. 31).

Considerando seu caráter multifacetado, para Kleba e Wendausen (2009, p. 735) o empoderamento envolve aspectos cognitivos, afetivos e de conduta e

Significa aumento do poder, da autonomia pessoal e coletiva de indivíduos e grupos sociais nas relações interpessoais e institucionais, principalmente daqueles submetidos a relações de opressão, discriminação e dominação social.

No campo da diabetologia, a formulação do empoderamento nos Estados Unidos recua ao início dos anos 1990, quando o Comitê de Educação do Centro de Pesquisa e Treinamento em Diabetes da Universidade de Michigan concluiu que a tradicional abordagem baseada na obediência (compliance) era inapropriada para a prática e avaliação da educação do paciente diabético (Anderson et al.,1995, p. 943).

Além disso, desde a década de 1990 a literatura internacional começa a constatar que a transmissão de informação por meio da prática educativa não é suficiente para habilitar a pessoa diabética no cuidado de si (Cyrino; Schraiber; Teixeira, 2009, p. 94). Segundo Anderson et al. (1995) o empoderamento é um complemento necessário à educação tradicional para o cuidado do diabetes, não estando em competição com ela (Anderson et al., 1995).

O empoderamento não é a única tentativa de resposta ao grande dilema que a assistência ao diabetes tem representado para os agentes da biomedicina. A discussão em torno da substituição do modelo da compliance pelo modelo da adherence também faz parte desse quadro.

Na verdade, como esclarecem Leite e Vasconcelos (2003, p. 777) em artigo sobre os significados adotados para o fenômeno da "adesão" e os fatores a ele relacionados, apesar de variar entre diversos autores, de modo geral, o conceito de adesão "é compreendido como a utilização dos medicamentos prescritos ou outros procedimentos [...] observando horários, doses, tempo de tratamento”. No levantamento dos artigos científicos sobre o tema, notou-se que os termos usados refletem a compreensão do papel dos atores no processo de adesão. Assim, na língua inglesa compliance poderia ser traduzido por obediência, e refere-se a um paciente passivo, enquanto adherence, ou aderência, enfatizaria a ideia da escolha livre do paciente em aceitar as recomendações do tratamento. Neste último caso um papel mais ativo do paciente estaria em evidência.

Como apontam Lutfey e Wishner (1999), a linguagem usada nos estudos sobre compliance fixa a ideia do "paciente submisso obedecendo a um médico autoritário" - o comportamento dos pacientes geralmente é descrito como negligente, de recusa, desviante e não cooperador. A avaliação do não cumprimento do tratamento acaba ganhando um teor moral: "um paciente noncompliant é também um paciente 'mau' ou 'difícil”' (Lutfey; Wishner, 1999, p. 637).

Cyrino, Schraiber e Teixeira (2009) mostram como a noção da obediência foi substituída pela de aderência, um conceito considerado central no tratamento das doenças crônicas. Passa-se a valorizar a experiência do paciente com a enfermidade, o conhecimento que ele adquire sobre como ela afeta seu cotidiano e como responde ao tratamento. Com isso, as condições de assimetria caracterizadas pelo poder médico de um lado, e a submissão do paciente de outro, são questionadas - o modelo da aderência rejeita a ideia de "obediência ao médico" para, em seu lugar, priorizar a "aceitação do tratamento" pelo paciente (Cyrino; Schraiber; Teixeira, 2009).

Para Lutfey e Wishner (1999), a mudança para a abordagem da aderência requer reestruturação da relação médico-paciente. Para facilitar esse processo é preciso considerar os pacientes como "participantes mais ativos em seu próprio cuidado" (p. 637), o que teria um significado especial no caso do diabetes, já que os pacientes têm a responsabilidade de gerir seus mal-estares de forma independente.

O conceito de aderência estaria relacionado a uma atitude de boa vontade para uma "comunicação mais aberta" e para o "trabalho mais colaborativo dos profissionais com os pacientes". Dessa forma, a estratégia seria a de que o médico pudesse sugerir ajustes a partir das dificuldades relatadas pelo paciente, tornando o tratamento mais factível e aceitável a este (Lutfey; Wishner, 1999, p. 637).

Na perspectiva de Glasgow e Anderson (1999), o empoderamento do paciente é mais adequado do que a simples mudança do modelo da compliance para o da adhrerence. 
Contando com farta produção que se estende até os dias atuais, Robert Anderson e Martha Funnell têm colaborado em reflexões acerca do aprofundamento teórico do paradigma do empoderamento ${ }^{6}$. Não há espaço aqui para uma revisão detalhada desse percurso, mas algumas questões importantes devem ser apontadas: a ideia de colaboração entre provedor de cuidado e paciente, cada qual com expertises igualmente importantes (Anderson; Funnell, 2010, p. 279); o reconhecimento do direito do paciente em tomar decisões que façam sentido no contexto de suas vidas, em lugar dos objetivos estabelecidos pelos profissionais da saúde (Anderson; Funnell, 2005, p. 154); o educador em diabetes assume mais a figura de um facilitador para os ajustes diante das dificuldades sentidas, intermediando os pressupostos da boa saúde com as necessidades e objetivos do paciente (Anderson, 1995, p. 414). Desse modo, o educador ajuda o paciente a desenvolver seu próprio plano de cuidado com o diabetes (Anderson et al., 1991, p. 585). De forma geral, o empoderamento representa a radicalização dos princípios básicos do modelo da aderência, propondo uma revisão profunda da estrutura das relações de assistência médica.

A "autonomia individual” e a "capacidade de fazer escolhas informadas" são ideias chave no discurso sobre o empoderamento. Para Anderson (1995, p. 413), são os pacientes que se encarregam do cuidado do diabetes na vida diária, considerando o fato de que os cuidados no tratamento do diabetes afetam virtualmente todos os aspectos de suas vidas, implicando uma substancial remodelação da forma de vida.

Com essas considerações, verifica-se que a noção de empoderamento referida por Anderson e Funnell é bastante específica e circunscrita às reflexões em torno de uma nova perspectiva da relação paciente-provedores de cuidado. Essa noção refere-se às transformações profundas nos comportamentos individuais dos pacientes em relação ao modo de lidar com a proposta de tratamento para o diabetes. Nesse sentido, o empoderamento não se refere à ideia do empoderamento comunitário que integra o sentido moderno da promoção da saúde. Também não se liga pelo menos não diretamente - ao sentido de aquisição de consciência política para capacitar o indivíduo a atuar na promoção das transformações dos determinantes estruturais de suas condições de saúde. Entretanto, como procura-se mostrar mais adiante, essa perspectiva tensiona de tal forma determinados princípios do modelo médico tradicional da relação médico-paciente a ponto de representar um grande desafio para o sistema de assistência à saúde, ou seja, é um desafio de dimensões estruturais.

$\mathrm{O}$ artigo Learning to empower patients (Anderson et al., 1991) tornou-se uma referência central para a análise proposta neste artigo. Ele avalia um curso voltado a educadores em diabetes, tema que não encontra o mesmo foco analítico na extensa produção de Robert Anderson e seus colaboradores. O que chama especialmente a atenção nesse texto é a forma como os autores problematizam os desafios que a perspectiva do empoderamento representa para os próprios profissionais da saúde. Mas, além disso, o texto é muito significativo por estruturar-se a partir das técnicas dirigidas ao desenvolvimento das habilidades dos educadores. Isso explica por que um texto relativamente antigo na produção desses autores tem um lugar central para as elaborações aqui apresentadas.

A análise que segue orienta-se pela interpretação de determinadas questões apontadas, sobretudo no referido texto, à luz de abordagens teóricas que chamam atenção para dimensões sociais que incidem sobre as relações de assistência à saúde.

\section{O caráter moral da ação de cuidado}

Anderson et al. (1991) tratam de como o educador deve ajudar os pacientes a se empenharem em projetos específicos para alcançarem seus objetivos. Como "conselheiro" o educador não deve direcionar ou controlar esse processo, mas, sim, agir como um "facilitador", procurando ser perspicaz e sensível para inferir - a partir de sua própria experiência, e a partir do tom de voz, postura, e expressões faciais

6 Os autores consideram-se filiados à perspectiva educacional de Paulo Freire, entendendo que a educação conduz à liberdade e à autonomia, e assim, ao empoderamento (Anderson; Funnell, 2010). Entre outras perspectivas importantes, os autores se apoiam no trabalho de Carl Rogers em torno da relação emocional no aconselhamento (Anderson; Funnell, 20o8); na teoria da autodeterminação (self-determination), que considera a importância do significado pessoal para a adoção de um determinado comportamento (Funnell; Tang; Anderson, 2007). 
do paciente - a melhor forma de explorar e resolver os problemas apresentados pelo tratamento.

Entre os comentários sobre o processo pedagógico do curso, sugere-se o cuidado para que os educadores evitem um comportamento de julgamento, o qual não faria parte da postura ideal do educador diante do paciente (Anderson et al., 1991, p. 586).

A atitude de "facilitador" que equaciona a prestação de auxílio ao modo como o paciente define e sente seus problemas com o diabetes leva os autores a se referirem a uma relação de maior proximidade entre paciente e provedor de cuidado. Algo que implica uma temporalidade própria, um processo que requer tempo para se desenvolver e que ocorre no ritmo do relato das experiências.

Esse processo está muito próximo de como Annemarie Mol (2008) caracteriza a "lógica do cuidado". Analisando alguns aspectos da assistência médica do diabetes na Holanda, Mol (2008) problematiza a lógica que rege o cuidado com a saúde. A autora procura construir o sentido do bom cuidado à medida que aponta as diferenças entre as lógicas do cuidado e da escolha.

Diferentemente da lógica da escolha, feita em momentos específicos, na lógica do cuidado a escolha é um processo contínuo, constituído por idas e vindas. "O cuidado não é uma transação na qual algo é trocado (um produto por um preço); mas uma interação em que a ação vai e volta"7 (Mol, 2008, p. $21)^{8}$. Na lógica do cuidado é difícil prever o que vai funcionar e o que não vai, o que implica em cuidadosa experimentação - a disposição para "tentar, ficar atento para o que acontece, adaptar tal coisa, e tentar novamente" (Mol, 2008, p. 61-62).

É importante considerar o fato de que o caráter de cronicidade aplica-se "às condições de saúde que podem ser gerenciadas, mas não curadas, apresentando sintomas contínuos ou periódicos que, de certo modo, podem interferir em várias dimensões da vida do adoecido e no seu entorno" (Canesqui, 2007, p. 20). Desse modo, o objetivo do tratamento é o de manter o "controle" da enfermidade, para o qual converge uma série de práticas constantes de cuidado que passam a caracterizar a vida das pessoas, as quais, por sua vez, são condicionadas por fatores individuais e cotidianos. Essa condição é responsável pelo tom da tenacidade e adaptabilidade que acaba caracterizando as práticas do cuidado no caso do diabetes, as quais não têm fim e sempre são desafiadas pela sucessão de "dias bons" e "dias ruins".

Annemarie Mol lembra que a questão da "prática” é central na lógica do cuidado - o cuidar é uma prática. Segundo essa lógica, ser um ator é primeiramente uma questão prática. E mesmo o ato de fazer escolhas no âmbito do cuidado se converte em tarefa prática - pois uma ou outra forma de cuidado está implicada com sua implementação prática. A ação, portanto, é propriamente moral, e, como diz a autora, desconfortável: "Você faz o melhor, mas é impossível prever como uma tentativa de fazer o bem funcionará na prática” (Mol, 2008, p. 90).

Caracterizando melhor o caráter moral da ação, a autora explora a diferença entre a "lógica do cuidado" e a "lógica da escolha". Na lógica da escolha o julgamento acerca da melhor ação ou do melhor produto ocorre com o distanciamento das coisas oferecidas à escolha. A ação vem depois do julgamento: estabelecer o que é bom é uma questão de pesar e ponderar todos os argumentos possíveis a favor e contra um determinado curso da ação (Mol, 2008, p. 90). E é "mais fácil julgar algo fora de si mesmo: um monitor de glicemia, seringas ou uma caneta de insulina" (Mol, 2008, p. 93). Semelhante distanciamento é impossível no caso da lógica do cuidado. Pois, sendo o cuidado uma questão antes de tudo prática, sua ação não vem depois do julgamento, a própria ação é moral, os valores estão misturados com os fatos. Desse modo, na lógica do cuidado não é possível o mesmo distanciamento descrito no caso da lógica da escolha: não é possível, por exemplo, distinguir tão claramente a própria vida das tarefas que escolhemos incluir nela visando o cuidado de si. "Você está dentro da sua vida, você a vive. Você não pode desembaraçar-se dela e estabelecer sua qualidade a partir de uma distância” (Mol, 2008, p. 94).

Para a autora, essa diferença em relação ao julgamento se reverte em diferença na avaliação das

\footnotetext{
7 No segundo capítulo do livro The logic of care, Mol (2008) faz uma interessante discussão problematizando o significado das empresas se dirigirem a um paciente como cliente. Para isso a autora analisa um anúncio comercial sobre um monitor de glicemia.

8 Todas as citações dos textos consultados em língua inglesa foram traduzidas pela autora deste artigo.
} 
consequências da ação. A culpa faz parte da lógica da escolha e não do cuidado, pois quem escolhe é responsável pelas consequências da escolha. Diferentemente, em lugar da imposição da culpa, a lógica do cuidado pede tenacidade ao longo da combinação entre adaptação e perseverança. Se algo não funciona a questão não é procurar o culpado, mas pensar o que tentar em seguida (Mol, 2008, p. 91-92).

A culpa não combina com a ideia de cuidado como um processo que se desenvolve no tempo, com idas e vindas. A atitude de sensibilidade e atenção do educador, referida por Anderson et al. (1991), estaria de acordo com a perspectiva de Mol (2008) quanto ao fato de que a coisa mais difícil que a lógica do cuidado pede ao indivíduo é a capacidade de ser tanto tenaz quanto adaptável. É preciso ser desprendido, livrando-se da ilusão do controle: a despeito de toda dedicação, o paciente não controla o mundo.

Como se vê, as consequências de ideias como as de "autonomia do paciente", "capacidade para fazer escolhas informadas”, "enfermidade de autogestão”, são complexas implicando uma revisão, ao que parece deveras profunda, nas "disposições" dos atores constituídos e relacionados por meio da assistência à saúde. Sob a perspectiva da lógica do cuidado, existe muito mais a ser considerado para além do significado do indivíduo onerado com a responsabilidade pela própria saúde.

Ainda sob essa lógica, do lado do paciente trata-se de considerar novas disposições e sensibilidades para lidar com a própria vida - a vida marcada pela atitude de cuidado com a enfermidade, que implica tenacidade, resiliência, desprendimento. Do lado dos provedores de cuidado, e de acordo com essas mesmas disposições, trata-se de afastarem-se da posição de quem emite julgamento, substituindo-a pela disposição para estudar, junto com o paciente, as dificuldades, possibilidades e limites do cuidado do diabetes. Pois o paciente empoderado requer um sistema aberto ao diálogo, no qual encontre receptividade para suas histórias de dificuldade com o diabetes, a partir das quais se envolva num circuito de troca, recebendo sugestões para lidar com essas dificuldades, expressões de encorajamento e compreensão. Esse é o tom dos textos de Robert Anderson e de seus colaboradores.

\section{Nem controle, nem indiferença: uma outra forma de cuidar}

Em um trabalho de 1995, Robert Anderson menciona que suas explanações sobre o empoderamento "sempre produzem reações de resistência e desconforto" (Anderson, 1995, p. 412) por parte de médicos e de outros profissionais da saúde; em 2005 Anderson e Funnell mencionam novamente a questão de que o empoderamento é "sempre percebido como uma agressão a papeis e responsabilidades profissionais profundamente incrustrados" (Anderson; Funnell, 2005, p. 155). Neste mesmo trabalho os autores referem-se à dificuldade para a mudança de abordagem no cuidado do diabetes: as escolas médicas continuam socializando os médicos na abordagem própria ao cuidado das enfermidades agudas; se alguns médicos e profissionais do cuidado adotam abordagens alternativas, estes em geral se queixam da falta de apoio de seus colegas ou sistemas de assistência à saúde (p. 155). Um trabalho mais recente dos autores (Anderson; Funnell, 2010) é significativamente dedicado ao esclarecimento dos equívocos e mal-entendidos com que a perspectiva do empoderamento é adotada. Apesar dos resultados de uma pesquisa entre educadores em diabetes nos Estados Unidos apontar o empoderamento como a abordagem mais escolhida - dentro de um conjunto de 12 sugestões apresentadas aos entrevistados da pesquisa -, Anderson e Funnell apontam o fato de que a abordagem não é bem compreendida. A conclusão dos autores baseia-se em sua experiência na área, evocando questões e comentários que recebem de profissionais da saúde, declarações de artigos publicados e comentários dos próprios pacientes submetidos a programas de educação orientados para o empoderamento (Anderson; Funnell, 2010, p. 278). Enfim, sem negar o lugar de destaque que a abordagem do empoderamento tem ganhado como suporte teórico nas intervenções educativas, o trabalho corrobora o quão atual é o desafio que ela representa para a efetiva mudança nas relações de assistência ao diabetes.

Perscrutar os desafios que a abordagem do empoderamento lança aos profissionais da saúde e pacientes, suas dificuldades e incômodos, tem aqui 
o objetivo de acessar as formas sociais tensionadas, permitindo, assim, distinguir mais claramente alguns dos fatores que estão em jogo nas relações de assistência.

Como coloca Anderson (1995), no modelo tradicional, médico e paciente são alocados em campos opostos e complementares: a figura do médico ocuparia a posição de "ativo", "poderoso", "bem informado" e daquele que está no controle do processo de cuidado; a figura do paciente corresponderia à posição de "passivo", "obediente", "aceitoso" e "dependente do saber e da boa vontade do médico".

Com uma forma tão difusiva de tratamento, que se imiscui em muitas situações da vida do paciente, o diabetes acabou se tornando atualmente um dos focos de pressão sobre a perspectiva médica mais tradicional. Do paciente passa a se esperar capacidade e disposição para assumir o papel "de quem toma decisões".

O autor lembra que não se trata de os médicos abandonarem a responsabilidade pelo tratamento, mas, sim, de abandonarem a "ilusão" de que têm responsabilidade pela gestão do dia-a-dia do diabetes. É, de fato, muito significativo quando Anderson refere-se à apreensão dos médicos quando lhe perguntam; "Você não está falando sobre deixar os pacientes fazerem tudo o que quiserem, está?”. Para Anderson a pergunta revela uma visão ingênua acerca do papel do profissional da saúde, o qual evocaria a situação da oposição entre a figura de pais controladores e a de pais indiferentes. Nesse caso seria preciso reconhecer que a relação pai-filho não é apropriada para o cuidado adulto do diabetes, sendo preciso substituí-la por uma relação adulto-adulto (Anderson, 1995, p. 414).

$\mathrm{O}$ autor aponta o fato de que muitos diabéticos rejeitam o modo como são aconselhados sobre o cuidado do diabetes, e essa rejeição tem a ver com a forma desse aconselhamento, que evoca justamente o modo como se orientam os filhos. Ou seja, com o propósito de gerenciar os níveis de açúcar no sangue, médicos e outros profissionais da saúde "acabam tentando direcionar a conduta diária de grandes áreas da vida de seus pacientes (alimentação, atividade física, etc.), da mesma forma que os pais direcionam seus filhos" (Anderson, 1995, p. 413). Para o autor, o paciente resiste a ser dirigido, ordenado, controlado, ou censurado a respeito da conduta da vida diária (Anderson; Funnell, 2000; Anderson, 1995), uma forma característica de se tratar crianças, e que marcaria as práticas do modelo médico tradicional.

De forma geral, verifica-se que a perspectiva do empoderamento do paciente aponta um problema com a forma "prescrição", ligado ao tipo de relação que ela acaba estabelecendo, ao converter o médico ou outro provedor de cuidado em uma autoridade que deve ser "obedecida”. Essa autoridade evocaria aquela exercida pelos pais sobre os filhos na relação familiar; sendo que para essa transposição talvez colabore o fato de as prescrições se dirigirem a dimensões da vida íntima, por assim dizer, relacionadas aos hábitos alimentares e de atividade física. A situação representaria grande desconforto aos pacientes enquanto pessoas adultas.

É interessante relacionar essa situação com a análise que Duarte (1986) faz acerca da construção diferencial da pessoa sob o prisma da "classe de idade". Entre os grupos nos quais estuda o "nervoso", Duarte considera as famílias observadas como adult-centered. Nesse contexto o

respeito é fundamentalmente o reconhecimento duma plenitude de identidade que só é atingida pela ultrapassagem da idade adolescente, pelo casamento e pelo nascimento de filhos; ou seja, pela assunção das responsabilidades e da dignidade, inerentes à condição de uma família nova. Crianças e jovens encontram-se subordinados nos núcleos familiares e são pessoas apenas em um sentido relativo e expectante (Duarte, 1986, p. 182-183).

A valorizada senioridade passa "tanto para o homem como para a mulher, pela boa condução do trem doméstico" (Duarte, 1986, p. 183). Segundo o autor, a condição adulta é um valor cultural maior respeitado por todos os segmentos de idade. A ideia do "estatuto diferencial de adulto" chamou a atenção para o problema em questão, ou seja, a conquista de posição de responsabilidade e consequente autoridade do adulto pleno que erige sua própria família.

No contexto das chamadas doenças crônicas, não apenas a condição de enfermo passa a fazer parte da vida da pessoa, mas também a de paciente. Ou seja, 
a condição de paciente estrutura-se nas relações com os serviços de saúde por meio do processo de acompanhamento do quadro clínico do diabetes e dos resultados do tratamento. 0 indivíduo é inserido em um conjunto de relações engendradas pelas instituições médicas.

Ao que parece, determinadas relações tendem a evocar fortemente a condição de subordinação presente nos núcleos familiares, e podem carregar um caráter negativo por dois aspectos: (1) por instaurarem uma descontinuidade no padrão de relação que o indivíduo mantém na família e em outras instituições, enquanto adulto respeitável - a pessoa adulta se vê "infantilizada" no contexto das relações de assistência à saúde - e (2) por essa descontinuidade no padrão de relação não ser acompanhada pela reciprocidade que caracteriza as relações familiares - pois, se na família crianças e jovens são dependentes do cuidado dos adultos, no caso do diabetes o cuidado é delegado ao próprio indivíduo e será avaliado e cobrado dele na próxima consulta ${ }^{9}$. Quer dizer, qual a vantagem da subordinação sendo que é o próprio paciente que "faz tudo"? Pois, se a condição de subordinação do paciente aponta a vigência do modelo tradicional de assistência, então a autorresponsabilização descaracteriza a atenção recebida enquanto "cuidado".

Nesse tipo de deslocamento, é importante pensar sobre o que representa o caráter de longa duração da enfermidade. Pois, é interessante considerar que, no caso de um mal-estar agudo, a percepção da reciprocidade das instituições médicas fica mais evidente à medida que a pessoa se restabelece completamente após o tratamento prescrito. No mal-estar agudo a pessoa fica, de fato, muito dependente da instituição médica, e está mais afeita a mostrar-se obediente à prescrição.x

Qual é, então, o problema em passar a "frequentar" os serviços de saúde? Em participar mais intensamente desse conjunto de práticas e saberes sobre o tratamento do diabetes?

De modo geral, parece que essa é a questão com que se defrontam as perspectivas críticas acerca do modelo médico tradicional, o que nos remete ao desafio que representa para as instituições de assistência à saúde o envolvimento maior com os pacientes, o prolongamento no tempo das relações entre pacientes e profissionais da saúde, o aumento da interlocução entre eles, e da influência do saber médico na vida cotidiana das pessoas assistidas. Sob tais condições, a "tradução" das práticas de cuidado nos padrões da relação de filiação tem demonstrado ser insatisfatória.

Na antropologia, a análise das relações de assistência à saúde tem se apoiado na comparação dos modelos de indivíduo e pessoa, problematizando a diferença entre as representações dos agentes da biomedicina e dos pacientes. Como coloca Duarte (2003, p. 177), essas pesquisas em conjunto buscam esclarecer a "dinâmica de afirmação da racionalização biomédica em contraste com as dimensões holistas da representação ou vivência dos eventos de saúde/doença".

Essa linha de trabalho procura compreender as relações que se estabelecem nas instituições de assistência à saúde a partir do confronto entre modelos individualista e holista. A perspectiva teórica se apoia na obra de Dumont $(1997,2000)$, que, por meio de pesquisa sobre as castas indianas, propôs a compreensão das sociedades ocidentais a partir da orientação pelo valor do indivíduo. Dumont (200o) considera duas configurações básicas que seriam características das sociedades tradicionais e modernas:

Nas primeiras [...] o acento incide sobre a sociedade em seu conjunto, como Homem coletivo; o ideal define-se pela organização da sociedade em vista de seus fins (e não em vista da felicidade individual); trata-se, antes de tudo, de ordem, de hierarquia, cada homem particular deve contribuir em seu lugar para a ordem global, e a justiça consiste em proporcionar as funções sociais com relação ao conjunto.

Para as sociedades modernas, ao contrário, o Ser humano é o homem "elementar", indivisível, sob sua forma de ser biológico e ao mesmo tempo de sujeito pensante. Cada homem particular encarna, num certo sentido, a humanidade inteira. Ele é a

9 Nesse sentido a antropologia tem inspirado pesquisas críticas acerca das dificuldades específicas que o diabetes traz para a relação entre pacientes e médicos/profissionais da saúde. Cf.: Barsaglini, 2011; Saslavski, 2007; Pittman, 1999. 
medida de todas as coisas (num sentido pleno todo novo). 0 reino dos fins coincide com os fins legítimos de cada homem, e assim os valores se invertem. O que se chama ainda de "sociedade" é o meio, a vida de cada um é o fim (Dumont, 1997, p. 57).

Dessa forma, um dado fenômeno social pode ser avaliado conforme o valor determinante em questão gire em torno do indivíduo ou da sociedade (ou grupo).

Como coloca Velho (1999), as sociedades modernas apresentam dimensões e instâncias "desindividualizadoras”, que seriam, por exemplo, a religião, a participação em certas instituições e a família. Tem-se, então, a coexistência dos dois princípios nas experiências sociais. Confrontam-se em nossas sociedades

grupos portadores de visões de mundo mais "individualizantes" (autoconsiderados como mais "modernos" e "racionais"), associados às camadas sociais urbanas herdeiras da "grande tradição" erudita do pensamento ocidental, e grupos portadores de visões de mundo mais "holistas" (e portanto considerados de fora como mais "tradicionais" e "retrógrados”), associados a camadas sociais "periféricas" e em boa parte alheias à reprodução da "grande tradição" ocidental (Ropa e Duarte, 1985, p. 193-194).

É com base nessa perspectiva que se reúnem os estudos que exploram as condições do "encontro" de representações, interpretadas como opostas, nas instituições do campo de assistência à saúde - as dos agentes da biomedicina e as dos pacientes.

O caráter específico da questão apontada nesta seção diz respeito à dificuldade das instituições de saúde em dimensionar as relações de assistência considerando a condição de pessoa - e não de indivíduo - de que se revestem os pacientes. Um desafio que surge a partir de temporalidades e processos específicos relativos à assistência às doenças crônicas. Pesa sobre essa dificuldade o fato de que parte expressiva das pessoas enfermas encontra-se na vida adulta, na condição de pais, mães e avós, com suas identidades sendo fortemente marcadas por uma posição de poder e prestígio relacionada ao pertencimento ao grupo familiar. Essa posição de poder e prestígio ganha uma dimensão mais saliente na disposição para o estabelecimento de relações no contexto social - em geral - e no contexto da assistência à saúde - em particular.

\section{"Conversas" que desafiam a ordem}

Em relação às dificuldades dos educadores em diabetes se adaptarem à perspectiva do empoderamento, Anderson et al. (1991) consideram o fato de que suas disposições também precisam ser revistas, de modo a viabilizarem uma nova forma de relação com os pacientes.

Os educadores sentem basicamente duas dificuldades. A primeira delas é o incômodo causado pelos conteúdos emocionais dos problemas dos pacientes. Como visto anteriormente, é sobre os relatos do paciente que a equipe de saúde deve trabalhar para ajustar o tratamento, seguindo suas necessidades e experiência na gestão do mesmo. Ocorre, entretanto, que a maior interlocução entre o profissional da saúde e o paciente acaba necessariamente abrindo espaço para comentários de teor emocional, que acabam integrando o relato das dificuldades do tratamento. Os educadores relatam ser muito desconfortável estimular os pacientes a expressarem emoções como raiva, culpa, ressentimento ou medo.

Segundo Anderson et al. (1991), a grande dificuldade que os educadores sentem ao fazer face aos conteúdos emocionais dos pacientes ocorreria porque os profissionais da saúde são treinados para “resolver problemas”, e emoções não são problemas para serem resolvidos. Em vez disso, elas precisam ser exploradas, expressas, experienciadas e aceitas pelo paciente. Sob tal perspectiva, o educador seria um ouvinte sério, compassivo e empático (Anderson et al., 1991).

Cabe aqui questionar qual é o significado da “troca emocional”, ou da entrada de conteúdos emocionais, nas relações estabelecidas nas instituições de saúde.

Como referido anteriormente, um dos fatores da rejeição da forma prescritiva do tratamento estaria ligada à falta de reciprocidade. Seguindo essa lógica, não é de se admirar o despreparo e a estranheza - para não dizer o escândalo - com que conteúdos emocionais podem ser recepcionados pelos pro- 
fissionais da saúde. A situação de embaraço não revelaria exatamente a falta de inteligibilidade que tais conteúdos emocionais produzem em ambientes nos quais as relações são orientadas pela "frieza" do modelo individualista? Pois este seria mais afeito às relações de contrato, que se contrapõem ao tipo de relações características da intimidade, tendo a família como uma de suas formas exemplares. Essa, sim, afeita às trocas emocionais e de apoio mútuo ${ }^{10}$.

É significativo, aliás, que justamente profissionais da psicologia e da enfermagem estejam promovendo abordagens como a do empoderamento. No primeiro caso é óbvia a vinculação profissional com a dimensão emocional. No caso do profissional da enfermagem, nota-se sua maior proximidade junto ao paciente, sobretudo enquanto mediador na relação com o espaço institucional, com procedimentos técnicos e com o médico. Tal papel tornaria esse profissional mais próximo e sensível às dificuldades e necessidades do paciente, e muitas vezes seu ouvinte.

A segunda dificuldade dos educadores é a de deixar os pacientes resolverem seus próprios problemas. É difícil para eles se absterem do papel automático de aconselhamento acerca dos objetivos de autocuidado corretos, ou sobre a melhor forma de atingir um objetivo particular. Esse comportamento é mais adequado, segundo Anderson et al. (1991), quando responde a um pedido explícito do paciente.

É mais útil ajudar os pacientes a explorarem preocupações e considerarem questões tais como as relativas aos seus sentimentos, necessidades e valores relacionados a ter e a tratar o diabetes; as opções acessíveis de autocuidado do diabetes; as consequências de implementar (ou não implementar) cada uma dessas opções de autocuidado; e quais comportamentos de autocuidado estão dispostos a adotar. 0 educador deve facilitar e não dominar o processo de ajudar os pacientes a chegarem a uma decisão sobre buscarem seus próprios objetivos de cuidado do diabetes (Anderson et al., 1991, p. 586-587).

Fica claro pelo excerto acima que o atendimento ao paciente aproxima-se da forma de uma "conversa”, envolvendo a exposição de pontos de vista dos vários aspectos que envolvem as dificuldades no tratamento.

Na pesquisa sobre o "nervoso", Duarte (1986) menciona a valorização da "boa conversa" entre seus pesquisados. Na verdade, muitas vezes suas entrevistas com eles eram "seguidas de agradecimentos por ter[em] podido "botar tantas coisas para fora" (Duarte, 1986, p.163). Fazendo referência à experiência de pesquisadoras psicólogas que trabalhavam com a mesma população, o autor lembra que elas também se viram às voltas com a maior produtividade das situações informais. A valorização da conversa para o alívio do nervoso, entretanto, não se transferia aos atendimentos psicológicos: "A ideia de conversas com hora marcada e num contexto ambulatorial parecia particularmente esdrúxula, pelo que raramente tinham continuidade os "tratamentos' assim propostos” (Duarte, 1986, p. 163).

Para Anderson et al. (1991), seria necessário que educadores desenvolvessem novas fontes de satisfação pessoal e profissional, aprendendo a valorizar seu papel de facilitadores educacionais tanto quanto - senão mais do que - o de solucionadores de problemas. No programa de formação de educadores, muitos deles tiveram que lutar para mudar comportamentos e conceitos profundamente enraizados para poderem usar as habilidades de aconselhamento para o empoderamento. Ou seja, mudar o comportamento e a postura para com o paciente envolve um processo delicado de transformação das disposições que orientam a atuação dos educadores, incluindo os valores pelos quais avaliam sua conduta e o desempenho de seus papéis profissionais ${ }^{11}$.

10 Ao discutir a oposição entre a casa e a rua, buscando alcançar os princípios sociológicos subjacentes às relações sociais e instituições no contexto brasileiro, DaMatta (1997, p. 95) coloca: "O traço distintivo do domínio da casa parece ser o maior controle das relações sociais, o que certamente implica maior intimidade e menor distância social. Minha casa é o local da minha família, da 'minha gente' ou 'dos meus', conforme falamos coloquialmente no Brasil”.

11 É interessante confrontar o desafio que as mudanças para o empoderamento representa com o jogo do "como se”, que Saslavski (2007) presenciou nas consultas que observou em sua pesquisa na Argentina. Através de uma espécie de acordo que rege a atuação nas consultas, médico e paciente restauram a ordem que, a cada vez, é ameaçada pela ineficácia do tratamento do diabetes. Relegam-se à penumbra as incertezas que essa ineficácia traz: o médico reitera as recomendações, e o paciente se cala acerca das contradições que sua experiência atesta, renovando a promessa de cumprimento do tratamento (Saslavski, 2007). 


\section{Considerações finais}

A análise da abordagem do empoderamento dos pesquisadores ligados à Universidade de Michigan, a partir da consideração dos valores do individualismo e do holismo, e também da lógica do cuidado, mostra que existem implicações profundas nas mudanças propostas. Essas mudanças não se referem apenas à disposição para incluir as práticas de cuidado definidas pelo tratamento médico, mas requerem a reestruturação das relações que se estabelecem na prática da assistência à saúde. Como visto, essas relações passam a requerer matizes mais holistas, na medida em que conteúdos ligados à experiência dos pacientes são considerados importantes para a estruturação do tratamento. Este passa a ser considerado como o resultado de uma negociação entre a perspectiva biomédica do "bom cuidado" e as necessidades e objetivos do paciente.

Os efeitos dessa perspectiva parecem bastante amplos no que diz respeito à estrutura institucional, envolvendo a pressão sobre as posições de autoridade dos agentes da biomedicina: a experiência do paciente no cuidado de si é legitimada e levada em conta no processo institucional; relativiza-se a responsabilidade do médico e dos profissionais da saúde sobre o controle da enfermidade.

Existe certa preocupação da literatura em alertar para o fato de que o foco no empoderamento - tal como no caso das iniciativas "educacionais" da promoção da saúde, focalizadas no estilo de vida (Westphal, 2006) - não deve se resumir a propostas que se concentram nas atitudes dos sujeitos, deixando de lado os aspectos sociais estruturais que envolvem a condição de vida saudável (Anderson, 1996). Nesse aspecto, entretanto, a presente análise tende a mostrar o quanto essas dimensões - a da ação dos sujeitos e a das estruturas sociais - não se mostram estanques uma em relação à outra, ou seja, as disposições e atitudes dos sujeitos exercem pressão sobre as formas institucionais. A esse respeito, analisando os vários sentidos da categoria empoderamento, Carvalho (2004, p. 1092) afirma que o chamado "empoderamento comunitário" reconhece a "mútua relação de condicionamento e determinação entre as macroestruturas e a ação de sujeitos individuais e coletivos".
A análise aqui empreendida mostrou que as propostas de mudança das condutas individuais, no sentido do empoderamento, podem se vincular de maneira significativa com as formas estruturais das instituições. A maior autonomia do paciente no cuidado do diabetes requer que as instituições remodelem suas práticas de assistência, no sentido de se orientarem pela lógica do cuidado. A assistência ao paciente mais autônomo no cuidado de si implica mais do que a pressão sobre os papéis e práticas dos atores envolvidos - como é o caso da concentração de poder na relação pacientes-provedores de cuidado -, ela implica uma mudança qualitativa na forma de apoio oferecido pelas instituições de saúde.

O modelo biomédico do "autocuidado" se abriria para a negociação, abandonando seu caráter prescritivo, para ser acionado no contexto da "conversa", e ajustado às necessidades e prioridades definidas pelo próprio paciente. O cuidado modelar-se-ia, enfim, por meio de relações que apresentam teores mais acentuados no sentido da troca, da reciprocidade.

\section{Referências}

ANDERSON, J. M. Empowering patients: issues and strategies. Social Science and Medicine, Oxford, v. 43, n. 5, p. 697-705, 1996.

ANDERSON, R. M. Patient Empowerment and the Traditional Medical Model: a case of irreconcilable differences? Diabetes Care, Alexandria, v. 18, n. 3 , p. 412-415, 1995.

ANDERSON, R. M.; FUNNELL, M. M. Compliance and adherence are dysfunctional concepts in diabetes care. The Diabetes Educator, Chicago, v. 26, n. 4, p. 597-604, 2000.

ANDERSON, R. M.; FUNNELL, M. M. Patient empowerment: reflections on the challenge of fostering the adoption of a new paradigm. Patient Education and Counseling, Limerick, v. 57, n. 2, p. 153-157, 2005 .

ANDERSON, R. M; FUNNELL, M. M. The art and science of diabetes education: a culture out of balance. The Diabetes Educator, Chicago, v. 34, n. 1, p. 109-117, 2008. 
ANDERSON, R. M; FUNNELL, M. M. Patient empowerment: myths and misconceptions. Patient Education and Counseling, Limerick, v. 79, n. 3, p. 277-282, 2010.

ANDERSON, R. M. et al. Learning to empower patients: results of professional education program for diabetes educators. Diabetes Care, Alexandria, v. 14, n. 7, p. 584-59o, 1991.

ANDERSON, R. M. et al. Patient Empowerment: results of a randomized controlled trial. Diabetes Care, Alexandria, v. 18, n. 7, p. 943-949, 1995.

BARSAGLINI, R. A. As representações sociais e a experiência com o diabetes: um enfoque socioantropológico. Rio de Janeiro: Fiocruz, 2011.

BUSS, P. M. Uma introdução ao conceito de promoção da saúde. In: CZERESNIA, D.; FREITAS, C. M. Promoção da saúde: conceitos, reflexões, tendências. Rio de Janeiro: Fiocruz, 2009. p. 19-42.

CANESQUI, A. M. Estudos antropológicos sobre os adoecidos crônicos. In: Olhares socioantropológicos sobre os adoecidos crônicos. São Paulo: Hucitec, 2007. p. 19-51.

CARVALHO, S. R. Os múltiplos sentidos da categoria "empowerment" no projeto de Promoção à Saúde. Cadernos de Saúde Pública, Rio de Janeiro, v. 20, n. 4, p. 1088-1095, 2004.

CARVALHO, S. R.; GASTALDO, D. Promoção à saúde e empoderamento: uma reflexão a partir das perspectivas crítico-social pós-estruturalista. Ciência \& Saúde Coletiva, Rio de Janeiro, v. 13, p. 2029-2040, 2008. Suplemento 2.

CYRINO, A. P.; SCHRAIBER, L. B.; TEIXEIRA, R. R. A educação para o autocuidado no diabetes mellitus tipo 2: da adesão ao "empoderamento". Interface - Comunicação, Saúde, Educação, Botucatu, v. 13, n. 30, p. 93-106, 2009.

DAMATTA, R. Carnavais, malandros e heróis: para uma sociologia do dilema brasileiro. Rio de Janeiro: Rocco, 1997.

DUARTE, L. F. D. Da vida nervosa nas classes trabalhadoras urbanas. Rio de Janeiro: Jorge Zahar; Brasília, DF: CNPq, 1986.
DUARTE, L. F. D. Indivíduo e pessoa na experiência da saúde e da doença. Ciência \& Saúde Coletiva, Rio de Janeiro, v. 8, n. 1, p. 173-183, 2003.

DUMONT, L. Homo hierarchicus: o sistema de castas e suas implicações. São Paulo: EDUSP, 1997.

DUMONT, L. O individualismo: uma perspectiva antropológica da ideologia moderna. Rio de Janeiro: Rocco, 2000.

FEATHERSTONE, M. The body in consumer culture. In: FEATHERSTONE, M.; HEPWORTH, M.; TURNER, B. S. (Ed.). The body: social process and cultural theory. London: Sage, 1991. p. 170-196.

FOUCAULT, M. História da sexualidade I: a vontade de saber. Rio de Janeiro: Graal, 1988.

FUNNELL, M. M.; ANDERSON, R. M. Changing office practice and health care systems to facilitate diabetes self-management. Current Diabetes Reports, Philadelphia, v. 3, n. 2, p.127133, 2003a.

FUNNELL, M. M.; ANDERSON, R. M. Patient empowerment: a look back, a look ahead. The Diabetes Educator, Chicago, v. 29, n. 3, p. 454-464, $2003 b$.

FUNNELL, M. M.; TANG, T. S.; ANDERSON, R. M. From DSME to DSMS: developing empowermentbased diabetes self-management support. Diabetes Spectrum, Alexandria, v. 20, n. 4, p. 221226, 2007.

GLASGOW, R.; ANDERSON, R. M. In diabetes care, moving from compliance to adherence is not enough: something entirely different is needed. Diabetes Care, Alexandria, v. 22, n. 12, p. 20902091, 1999.

KLEBA, M. E.; WENDAUSEN, A. Empoderamento: processo de fortalecimento dos sujeitos nos espaços de participação social e democratização política. Saúde e Sociedade, São Paulo, v. 18, n. 4, p. 733-743, 2009.

LEITE, S. N.; VASCONCELLOS, M. P. C. Adesão à terapêutica medicamentosa: elementos para a discussão de conceitos e pressupostos adotados pela literatura. Ciência \& Saúde Coletiva, Rio de Janeiro, v. 8, n. 3, p. 775-782, 2003. 
LOPES, A. A. F. Assumindo o cuidado de

si: identidade e práticas associativas entre

diabéticos. 2010. Tese (Doutorado em Antropologia

Social) - Instituto de Filosofia e Ciências Humanas

da Universidade Estadual de Campinas, Campinas, 2010.

LUTFEY, K.; WISHNER, W. J. Beyond "compliance" is "adherence": improving the prospect of diabetes care. Diabetes Care, Alexandria, v. 22, n. 4, p. 635-

$639,1999$.

MOL, A. The logic of care: health and the problem of patient choice. London: Routledge, 2008.

PITTMAN, P. Género y calidad de atención: el caso de hipertensión y diabetes en Avellaneda, Provincia de Buenos Aires, Argentina. Washington, DC: Organización Panamericana de la Salud; OMS, 1999.

RABINOW, P. Artificialidade e iluminismo: da sociobiologia à biossociabilidade. In:

Antropologia da Razão. Rio de Janeiro: RelumeDumará, 2002. p. 135-157.
ROPA, D.; DUARTE, L. F. D. Considerações teóricas sobre a questão do "atendimento psicológico" às classes trabalhadoras. In: FIGUEIRA, S. A. (Org.). Cultura e psicanálise. São Paulo: Brasiliense, 1985. p. 178-201.

ROSE, N. The politics of life itself. Theory, Culture \& Society, London, v. 18, n. 6, p. 1-30, 2001.

ROSE, N. The politics of life itself: biomedicine, power, and subjectivity in the twenty-first century. Princeton: Oxford: Princeton University Press, 2007.

SASLAVSKI, L. C. Por que no se cura (todavía) la diabetes?: un abordaje antropológico de la enfermedad considerada la epidemia del siglo XXI. Buenos Aires: Antropofagia, 2007.

VELHO, G. Projeto, emoção e orientação em sociedades complexas. In: Individualismo $e$ cultura: notas para uma antropologia da sociedade contemporânea. 5. ed. Rio de Janeiro: Jorge Zahar, 1999. p. 13-37.

WESTPHAL, M. F. Promoção da saúde e prevenção de doenças. In: CAMPOS, G. W. S. et al. (Org.).

Tratado de saúde coletiva. São Paulo: Hucitec; Rio de Janeiro: Fiocruz, 20o6. p. 635-667.

\section{Agradecimentos}

Agradeço à Profa. Ana Maria Canesqui e aos integrantes do Grupo de Pesquisa "Cultura, Saúde, Doença", por ela coordenado, pelas críticas e sugestões com as quais a presente versão se beneficiou.

Recebido: $24 / 11 / 2013$

Reapresentado: 21/07/2014

Aprovado: 21/08/2014 